\title{
MULTICHARME: A modified Chernin-type multi-pass cell designed for IR and THz long-path absorption measurements in the CHARME atmospheric simulation chamber.
}

Jean Decker ${ }^{1}$, Éric Fertein ${ }^{1}$, Jonas Bruckhuisen ${ }^{1}$, Nicolas Houzel ${ }^{1}$, Pierre Kulinski ${ }^{1}$, Bo Fang $^{2}$, Weixiong

5 Zhao $^{2}$, Francis Hindle ${ }^{1}$, Guillaume Dhont ${ }^{1}$, Robin Bocquet ${ }^{1}$, Gaël Mouret ${ }^{1}$, Cécile Coeur ${ }^{1}$ and Arnaud Cuisset $^{1}$

${ }^{1}$ Laboratoire de Physico-Chimie de l'Atmosphère, UR4493, LPCA, Université du Littoral Côte d'Opale, F-59140 Dunkerque, France.

${ }^{2}$ Laboratory of Atmospheric Physico-Chemistry, Anhui Institute of Optics and Fine Mechanics, HFIPS, Chinese Academy of

10 Sciences, Hefei 230031, Anhui, China

Correspondence to: Arnaud Cuisset (arnaud.cuisset@univ-littoral.fr)

\begin{abstract}
We have developed MULTICHARME, a modified Chernin-type multi-pass cell especially designed for IR and THz long-path absorption measurements in the CHamber for Atmospheric Reactivity and Metrology of the Environment (CHARME). By

15 measuring the output power using a near-IR diode-laser and a $\mathrm{THz}$ amplified multiplication chain, we have established that the effective reflectivity of MULTICHARME is better than $94 \%$ over approximately three decades of frequency. Absorption measurements of $\mathrm{N}_{2} \mathrm{O}$ have been performed by probing highly excited rovibrational transitions in the near-IR and ground state rotational transitions at submillimetre wavelengths. In each case the linearity of the absorbance with the pathlengths was verified. Finally, we demonstrate that THz spectroscopy is able to study the isotopic composition of greenhouse polar gases such as $\mathrm{N}_{2} \mathrm{O}$ and to absolutely quantify stable $\left(\mathrm{N}_{2} \mathrm{O}\right)$ and reactive $\left(\mathrm{O}_{3}\right)$ species at trace levels. Moreover, a THz monitoring at low pressure of the ozone decay in the chamber has been performed. The deduced ozone lifetime of $3.4 \pm 0.1 \mathrm{~h}$ is shorter compared with previous measurements performed in CHARME at atmospheric pressure. For the first time, the ability of THz rotational spectroscopy to monitor, with a very high degree of selectivity, stable and reactive polar compounds at trace level in an atmospheric simulation chamber is demonstrated. However, the sensitivity of the THz monitoring needs to be improved

25 to reach the atmospheric trace levels. For this purpose, it is necessary to figure out the baseline variations as well as possible induced by the multiple standing waves present in MULTICHARME.
\end{abstract}

\section{Introduction}

Atmospheric Simulation Chambers (ASC) have been developed to study atmospheric physico-chemical processes under controlled conditions. Aside small Teflon bags of few hundred litres, approximately 35 chambers are currently in operation around the world. All these reactors are equipped with a large panel of instruments dedicated to the monitoring of 
gases and particles, ranging from commercially available apparatus to specialized laboratory developed setups offering in-situ measurement of chemical species by optical techniques.

Various spectrometers based on photonic sources from UV to mid-IR have been coupled to different ASCs allowing the stable and unstable reactants to be monitored along with the gas and particle phase products involved in key atmospheric reactions

35 (Barnes et al., 1994; Bloss et al., 2005 a,b; Rohrer et al., 2005; Wagner et al., 2006; Ren et al., 2017 a,b; Massabò et al., 2018). The identification of critical intermediate species and the time-resolved quantification yielding to kinetic parameters is of upmost importance for atmospheric models. The optical components used to couple the probe beam with the ASC are selected depending on the nature of the light source employed, the detection scheme and the geometry of the reactor. The trace gas monitoring requirement in an ASC makes it necessary to reach sub-ppm limits of detection (LOD) by maximizing the interaction path-length between the light and the probed species. Nowadays, most of the ASCs, using optical spectrometers as analysers, are equipped with an optical system enabling multiple passes of the probe light back and forth across the ASC, thus increasing the absorption path-length and consequently improving the LOD.

For example, several ASCs are coupled to commercially available Fourier-Transform infrared (FTIR) spectrometers for VOC detection at low-resolution $\left(>0.5 \mathrm{~cm}^{-1}\right)$ in the mid-IR (typically $400-4000 \mathrm{~cm}^{-1}$ ) using a White-cell multi-pass mirror configuration reaching several hundreds of meters of interaction pathlengths with a broadband black-body IR source. The following ASCs are well known examples in the EUROCHAMP 2020 network (EUROCHAMP 2020): (i) the $4.2 \mathrm{~m}^{3}$ CESAM chamber in Paris uses a globar source inside a Bruker interferometer with a $192 \mathrm{~m}$ pathlength White-cell (Wang et al., 2011); (ii) the quartz reactor QUAREC in Wuppertal also employs a White-cell configuration to achieve an optical path-length of $484.7 \pm 0.8 \mathrm{~m}$ and is entirely mounted inside the photoreactor for sensitive in situ long path IR absorption monitoring of 50 reactants and products (Barnes et al., 1994); (iii) the EUPHORE photoreactor in Valence makes it possible to intercompare 1 $\mathrm{cm}^{-1}$ resolution FTIR data $(\mathrm{L}=616 \mathrm{~m})$ with Differential Optical Absorption Spectroscopy measurements in the 389-469 nm UV range with a dedicated White-cell (W-DOAS) which can reach km path-lengths (Bloss et al., $2005 \mathrm{a}, \mathrm{b}$ ).

The HIRAC chamber in Leeds is coupled to a LIF-FAGE analyzer and to a multiple pass FTIR system. In contrast to the previous examples of traditional White-type arrangements, the HIRAC team chose a modified multiple pass matrix system developed by Chernin (Chernin, 2002). This solution retains the focal properties of the original White cell and perfectly conserves optical throughput over a range of matrix arrangements. In practice, the Chernin-cell is very easy to align, and shows very good stability to vibrations, with the FTIR giving good LODs over short acquisition times. For observation times as short as $1 \mathrm{~min}$, LODs below than $100 \mathrm{ppb}$ are obtained for ozone and VOCs such as acetaldehyde, methane, and formaldehyde with the FTIR interferometer coupled to the $128.5 \mathrm{~m}$ Chernin cell. (Glowacki et al., 2007) Finally, the Chernin multi-pass cell

60 optimizes the recirculation of the beam over many focused lines on the field mirrors and minimizes the overlapping between adjacent refocusing points.

Due to the lack of reliable and sufficiently powerful sources and due to the difficulty to control on long distances the propagation of more divergent beams, Far-IR/Terahertz(THz) spectrometers have never been used for trace gases monitoring in ASCs. Yet, in 2013, Kwabia Tchana et al. have demonstrated the ability to perform FT-Far-IR spectroscopy in a large 

synchrotron (Brubach et al. 2010) and allows mid- and far-IR measurements with variable path-lengths from 3 to more than $141 \mathrm{~m}$ thanks to exceptional properties of brightness and weak divergence especially in the $\mathrm{THz}$ domain.

In this study, we present and characterize a multiple pass system developed for the CHamber for Atmospheric Reactivity and Metrology of the Environment (CHARME) (Fayad et al. 2019). Based on a Chernin type arrangement, the so named MULTICHARME has been dimensioned for the CHARME ASC and allows the monitoring of stable and reactive atmospheric species at trace levels over three decades of frequencies by probing long path rovibrational and rotational molecular absorbances respectively in the IR and in the THz domains. To the best of our knowledge, this is the first time that a THz spectrometer is used for in situ measurements of atmospheric species in an ASC. The preliminary results obtained in this study highlight a new approach based on pure rotational spectroscopy for rapid and highly selective detection of stable and reactive atmospheric compounds in a simulated atmospheric environment. The first part of the article will be dedicated to the description of CHARME, MULTICHARME and its coupling with IR and THz sources. Results are presented and discussed in the second part of the article with a special focus on the THz measurements which are unprecedented in the ASC community.

\section{Experimental setup and Methodology}

\subsection{CHARME (CHamber for Atmospheric Reactivity and Metrology of the Environment)}

80 CHARME is the new atmospheric simulation chamber designed in the LPCA (Laboratoire de Physico-Chimie de l'Atmosphère) laboratory in Dunkirk (France). CHARME is described in details in Fayad et al. 2019. Briefly it consists of a $9.2 \mathrm{~m}^{3}$ evacuable cylinder (length $\approx 4 \mathrm{~m}$; internal diameter $\approx 1.7 \mathrm{~m}$ ) made in electropolished stainless steel (304 L). The inner surface of the reactor is mechanically polished in addition to an electrochemical treatment, which enhances the light reflectivity and also reduces the interaction of gases and particles with the walls. Four stainless steel fans (diameter $50 \mathrm{~cm}$ ) located at the bottom of the chamber assure a fast homogenization of the reactive mixtures.

The rigid walls with a thickness varying from 4 to $40 \mathrm{~mm}$ permit the reactor to guarantee vacuum and non-deformation of the flanges. Consequently, CHARME is considered as vacuum compatible, and it is capable to support most of the mechanical constraints when it is under vacuum. The range of pressure under which it can operate is: 0.05 mbar $<\mathrm{P}<1000$ mbar. CHARME is pumped with a vacuum pump (Cobra NC0100-0300B) and is then filled till the required pressure with purified

90 and dried air using a generator (Parker Zander KA-MT 1-8). The pressure within the chamber is controlled using 2 MKS BARATRON (626B13MDE (1000 mbar) and 626B01MDE (1 mbar)) and a pressure reader (MKS PR4000B) and the relative humidity and temperature are monitored by a combined probe (Vaisala HUMICAP, HMT330).

CHARME has 9 different circular access ports ranging from 45 to $20 \mathrm{~cm}$ in diameter (see Fig. S1 in the Supplement), which are used for various tasks: to accommodate MULTICHARME optical setup for a Chernin-cell described in this article; to 95 provide physical access to the inside of the chamber for any cleaning and alignment operations; for in-situ monitoring of gases 
and particles by IBBCEAS (Incoherent Broad Band Cavity Enhanced Absorption Spectroscopy) (Meng et al., 2020)); to introduce gases and/or particles into the chamber.

\subsection{MULTICHARME (MULTI-pass cell specially designed for CHARME)}

\subsubsection{General design}

In order to ensure a sufficient optical throughput at THz frequencies the MULTICHARME Chernin-cell configuration employed uses two rectangular field mirrors $(266 \times 310 \mathrm{~mm}$ and $222 \times 50 \mathrm{~mm})$, and three circular objective mirrors (diameter $130 \mathrm{~mm}$ ). We have opted for the modified version of the Chernin cell with the input and output windows on both sides of the field mirrors (Chernin, 2002). MULTICHARME has been designed in order to maximize the size of the mirrors so as to anticipate the large size of the beams and the strong divergences at longer wavelengths in the $\mathrm{THz}$ domain. We were nevertheless limited by the size of the flanges coupled to the DN 450 circular ports of the CHARME ASC. All mirrors have the same radii of curvature $(\mathrm{ROC}=5000 \mathrm{~mm}$ ) corresponding to the MULTICHARME base-length. Fused silica substrate was used for the field mirrors, $\mathrm{K} 9$ for the objectives. To optimize the reflectivity from near-IR to THz domain i.e. three frequency decades from $300 \mathrm{THz}$ to $0.3 \mathrm{THz}$, a coating of $500 \mathrm{~nm}$ silver protected by $10 \mathrm{~nm}$ of $\mathrm{Al}_{2} \mathrm{O}_{3}$ was used. These relatively large mirrors were manufactured by the Anhui Institute of Optical and Fine Mechanics over a period of several months to build the substrates and to deposit the coatings.

The two optical mounts, equipped with the three objective mirrors and the two field mirrors, constitute the Chernin cell presented in Fig. 1. They are mounted at opposite ends of CHARME using the DN 450 access ports and custom manufactured vacuum enclosures placing the mirrors inside the chamber. Two aluminum optical mounts were constructed to hold the mirrors. The mass of the additional components added to CHARME was $160 \mathrm{~kg}$ for each of the two DN 450 ports located at the opposite ends.
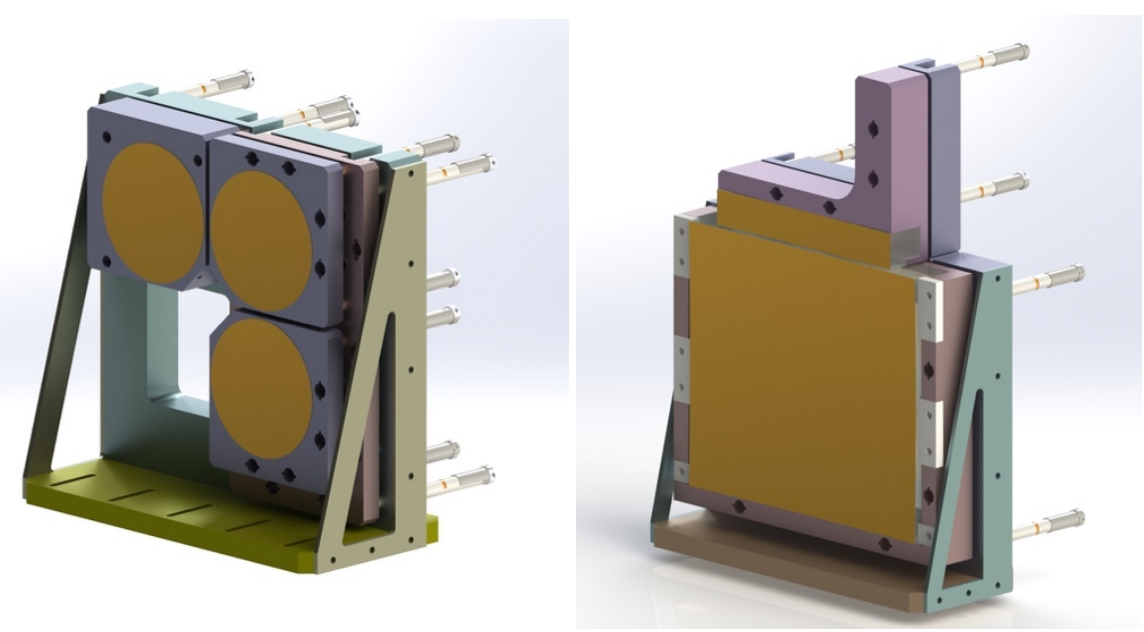

Figure 1. Schemes of the two mirror's blocks of MULTICHARME: the objective's block (left) and the field's block (right) 
A static analysis was performed to evaluate the gravity and vacuum pressure deformations. The maximal displacements have been estimated to be less than $30 \mu \mathrm{m}$. A picture of the five mirrors is given in Fig. S2 in the Supplement. The characterization of their reflectivity in the IR and in the THz domains is described in Sect. 2.2.2 and 2.2.3, respectively. In order to accurately and easily control the optical alignment and the pathlength, both the field and objective mirrors are equipped with computer-controlled micrometric screws: MULTICHARME may be aligned with 18 compact linear motorized actuators TRA25PP from the MKS/Newport company (six actuators are fixed on the field mount to adjust the three degrees of freedom of the two field mirrors; twelve actuators are on the objective mount: nine to control the position of the three objective mirrors and three to adjust the relative orientation between field and objective blocks). The actuators are controlled by a homemade ARDUINO based system located outside the cell (see Fig. S3 in the Supplement). This system allows to select independently each actuator and to control their moving. The five mirrors' configuration is easy to align, with very good stability to vibrations, and gave variable rows with even column images on the field mirrors. Different spot patterns obtained with a He-Ne alignment laser are shown in Fig. S4 in the Supplement highlighting our ability to adjust matrix arrangement on the field mirror for different pathlengths in MULTICHARME from $120 \mathrm{~m}$ to $540 \mathrm{~m}$.

\subsubsection{Coupling with IR tunable diode laser}

The characterization in the near-IR has been performed using a continuous-wave Extended Cavity Diode Laser (ECDL, Toptica DL pro) tunable from 1340 to $1450 \mathrm{~nm}$ with an output power of $80 \mathrm{~mW}$ power, a spectral width of $100 \mathrm{kHz}$ and a mode-hop free tuning range of $20 \mathrm{GHz}$. A standard photodiode connected to a oscilloscope was used for the detection.

135 The DL source, the photodetector and the transfer optics were placed on an optical breadboard fixed to the field flange. The IR input and output was coupled to the CHARME ASC by two 3 inch diameter ZnSe windows with a $1^{\circ}$ wedge giving a theoretical transmission of about $70 \%$ at $1.4 \mu \mathrm{m}$.

The IR optical configuration is presented in Fig. 2a, an additional mirror was inserted into the beam path to coaxially inject a red MKS/Newport He-Ne Laser $(5 \mathrm{~mW})$ with the IR beam axis in order to facilitate the alignment of the Chernin-cell.

140 This enables the IR pathlength in MULTICHARME to be evaluated by the observation of the matrix arrangement of the HeNe spots on the field mirrors observed from a BK7 window placed on the objectives transfer flange. All adjustments and pathlength changes can be made in situ, without venting CHARME, with the computer-controlled actuators. Once the laser was adjusted for the desired operating range a calibration was performed by recording a fiber coupled wavelength-meter (Burleigh WA-1500) offering a relative accuracy of $10^{-7}$ for the corresponding piezo-actuator voltages. Spectra were obtained

145 by applying a voltage ramp to the piezo actuator allowing to explore a range of $0.17 \mathrm{~cm}^{-1}$ around the center of the line at a frequency of $1.3 \mathrm{~Hz}$ while the received photodiode signal was averaged by a digital oscilloscope, the signal was typically accumulated over 16 ramp cycles. 
a)

b)
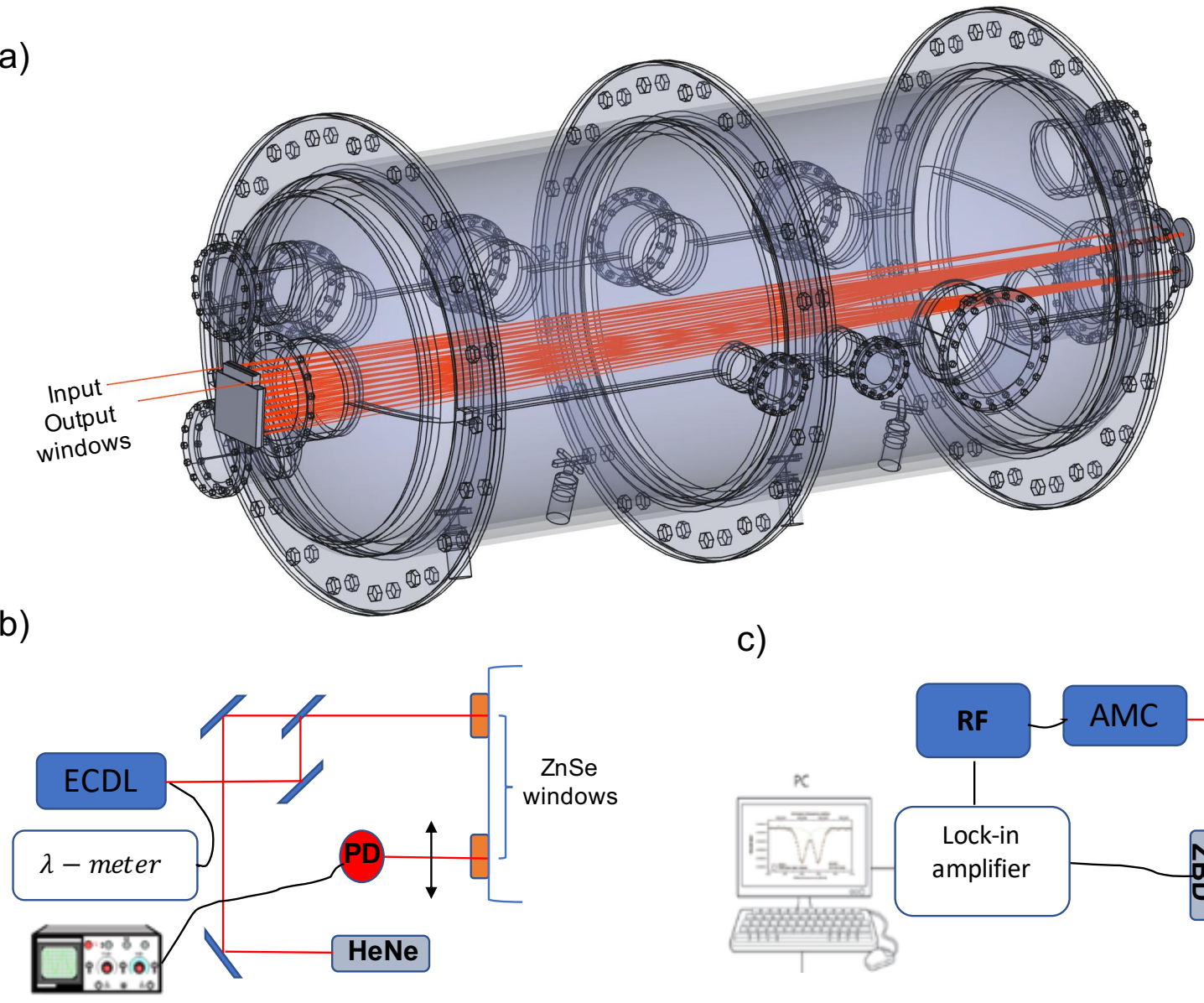

c)

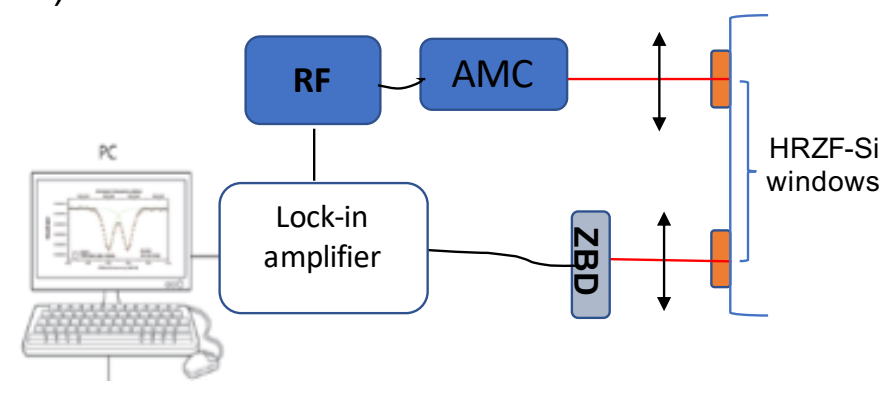

Figure 2. (a) 3D plot of MULTICHARME in CHARME performed with the FreeCad software and the Optics Workbench. (b) near-IR coupling to MULTICHARME via ZnSe windows using: an Extended Cavity Diode Laser (ECDL); a standard photodiode (PD); a He-Ne laser for alignment and a wavelength meter ( $\lambda$ - meter). (c) THz coupling to MULTICHARME via HRZF-Si windows using: an amplified multiplication chain (AMC) driven by a RF synthesizer; a zero-biased detector (ZBD) connected to a lock-in amplifier.

To characterize the performance of MULTICHARME in the near-IR, we have examined the optical throughput in the modified Chernin multi-pass cell by measuring the output IR power for several different matrix arrangements as suggested by Glowacki et al. in Ref. (Glowacki et al. 2007). It corresponds to 12 matrix configurations from 24 to 108 passes, for pathlengths from $120 \mathrm{~m}$ ( 3 rows $\times 4$ columns) to $540 \mathrm{~m}$ ( 9 rows $\times 6$ columns), respectively. The output powers shown in Fig. 3 were measured with a PDA400 power-meter from the Thorlabs company with an accuracy of $1.2 \mu \mathrm{W}$. The variation of the output power with the number of reflections was modelled by a power law $P=A * R_{e f f}{ }^{n}$, where A is a constant corresponding to 
the received power with no reflection, Reff is the effective mirror reflectivity at $1.4 \mu \mathrm{m}$ and $\mathrm{n}$ is the number of reflections. An effective reflectivity of the mirrors at $1.4 \mu \mathrm{m}$ was adjusted to $95.98 \pm 0.06 \%$ with a weighted fit using the estimated error bars taking into account the accuracy of the IR photodetector. This value is rather good considering the expected decrease of the IR reflectance at shorter wavelengths.
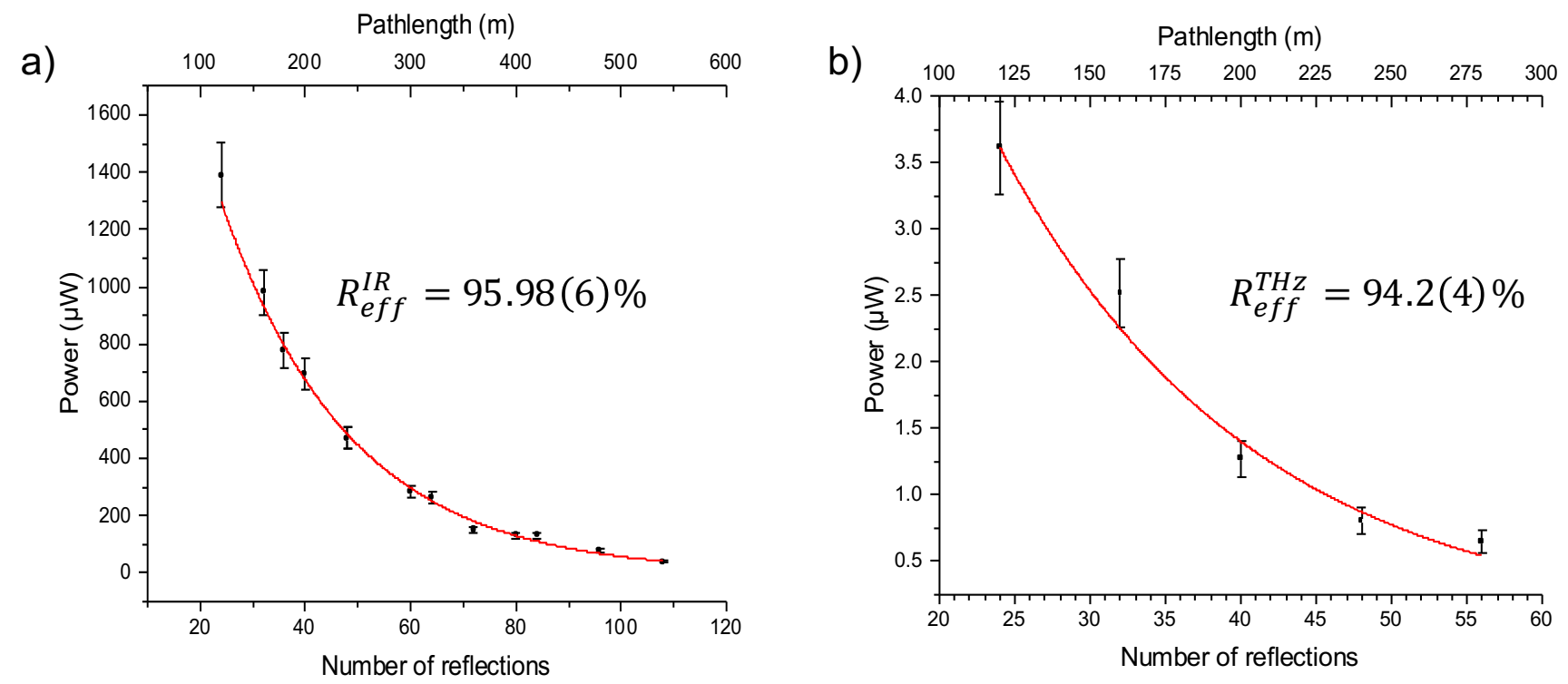

Figure 3. Attenuation of the IR (a) and the THz (b) output power vs the number of the reflections in MULTICHARME. The effective IR and THz reflectivities are deduced from the fit of the measurements with the power law: $P=A * R^{n}$. The uncertainties on the last digits are given in parentheses. The fits are performed with an instrumental weighting $\omega_{i}=1 / \sigma_{i}{ }^{2}$ with $\sigma_{i}$ the error bar sizes taking into account: the IR sensor uncertainty (5\%) and the accuracy of controller sensor (3\%) for (a) ; the THz power fluctuations measured on the lock-in amplifier for (b).

\subsubsection{Coupling with THz source}

Several compact and versatile solid-state subTHz sources are currently used in our laboratory for trace gas monitoring from high resolution rotational signatures of atmospheric pollutants in realistic media (Mouret et al. 2013, Hindle et al. 2018). In this study, a commercial Virginia Diode Inc amplified multiplication chain (AMC) driven by a microwave synthesizer (Rhodes \& Schwarz SMA 100B) was used. Two Menlo systems TPX lenses of 2" diameter and $100 \mathrm{~mm}$ focal length were used to collimate the beam at the entrance of the chamber and refocus the output beam onto the detector. The propagation of the $\mathrm{THz}$ radiation in MULTICHARME was modelled as a Gaussian beam using a program developed by Lightmachinery inc. showing that the use of $\mathrm{f}=100 \mathrm{~mm}$ lenses provides the best results taking into account the beam properties (waist and divergence), the dimension of MULTICHARME and the different losses (transmission through the windows \& reflections on the field and objective mirrors). Two different AMC multiplication stages were used, the first (multiplication $\times 18)$ to cover 
the 140 to $220 \mathrm{GHz}$ frequency region with an average power of $3 \mathrm{~mW}$ and the second (multiplication $\times 54$ ) to cover the 440 to $660 \mathrm{GHz}$ region with an output power of around $50 \mu \mathrm{W}$. To detect the MULTICHARME output THz signal, two VDI Schottky respectively for the first and the second stages. The typical Noise Equivalent Power (NEP) of these Schottky diodes is estimated to $10 \mathrm{pW} / \sqrt{\mathrm{Hz}}$. Both Amplitude Modulation (AM) or Frequency Modulation (FM) schemes were employed. The simultaneous use of AM and FM proved useful to minimise the effects of the standing waves in the baseline, (see Sect. 3). A computer controlled Ametek 7230 lock-in amplifier recovered the measured signal as a function the frequency. High resistivity silicon windows with a theoretical transmission of more than $50 \%$ were used for the entry and exit of MULTICHARME during the THz measurements. This material is opaque at the He-Ne wavelength, so the THz beam alignment in MULTICHARME was performed by superimposing the THz beam to the IR beam at the entrance of MULTICHARME and on the objective mirrors. As we did with the IR radiation, we have measured the THz output power for different pathlengths. These measurements presented in Fig. $3 \mathrm{~b}$ were performed around $190 \mathrm{GHz}$ corresponding to the maximal output power at the rank $\times 18$ of the AMC.

195 With a lower input power and a more divergent beam, only 5 matrix configurations corresponding to path-lengths from $120 \mathrm{~m}$ (24 passes) to $280 \mathrm{~m}$ (56 passes) were accessible at this frequency. If we consider just the detector NEP, $50 \mathrm{pW}$ should be detectable with a time constant of 1 s., i.e four orders of magnitude below the power level measured for a $280 \mathrm{~m}$ pathlength. Here the strong limitation to reach larger pathlengths is the important divergence of the THz radiation and the size of the THz waist on the field mirrors. However, we can reasonably think that longer interaction distances may be accessible at higher frequencies or with more powerful THz sources. Anyway, at millimeter wavelengths, to reach a pathlength of $280 \mathrm{~m}$ is already exceptional with a highly divergent source such as an amplified frequency multiplication chain. In Ref. [Cuisset \& al., 2021], an overview of the best performance reached by rotational submm-wave/THz long-path absorption spectroscopy is provided: the maximal $\mathrm{THz}$ pathlength in a White-cell was obtained with a weakly divergent and bright synchrotron source but it never exceeds $200 \mathrm{~m}$ (Brubach et al. 2010); longer interaction path-length are accessible only in Fabry-Perot resonators with intracavity spectroscopic techniques (Hindle et al. 2019). By fitting, with the power law, the THz output power, an effective $\mathrm{THz}$ reflectivity of $94.2 \pm 0.4 \%$ has been found for MULTICHARME. This value is only slightly lower than the near-IR value found in Fig. 2a. Therefore, MULTICHARME guarantees a reflectivity better than $94 \%$ on more than three decades of frequencies. With a unique modified Chernin type multi-pass cell, long path-absorption spectroscopic measurements are now possible from the THz to the near-IR domain in an ASC such as CHARME.

\section{Results and discussion}

\subsection{Absorption linearities}

The first spectroscopic measurements were carried out to verify the linearity of the absorption over three decades of frequencies from mm-wave to near-IR domains. In the aim to characterize the performances of MULTICHARME, we have 
chosen nitrous oxide $\mathrm{N}_{2} \mathrm{O}$ as molecule test for three main reasons: (i) $\mathrm{N}_{2} \mathrm{O}$ is a powerful and very stable greenhouse gas which can be considered now as the dominant ozone-depleting substance emitted in the $21^{\text {st }}$ century in our atmosphere (Ravishankara et al., 2009). The monitoring of its chemical activity during its transport from the troposphere to the stratosphere is crucial to control the ozone depletion; (ii) $\mathrm{N}_{2} \mathrm{O}$ is actually monitored in the troposphere and in the stratosphere by probing their rovibrational IR and rotational THz transitions with sounders such as IASI (Clerbaux et al., 2009) or TALIS (Wang et al., 2020), respectively; (iii) The molecular rotational and rovibrational line parameters (line frequencies, line widths, line intensities) of $\mathrm{N}_{2} \mathrm{O}$ were measured and calculated from the mm-wave to the near-IR domains and are listed in the international spectroscopic databases such as JPL (Pickett et al. 1998, THz data) or HITRAN (Gordon et al. 2022, IR data).
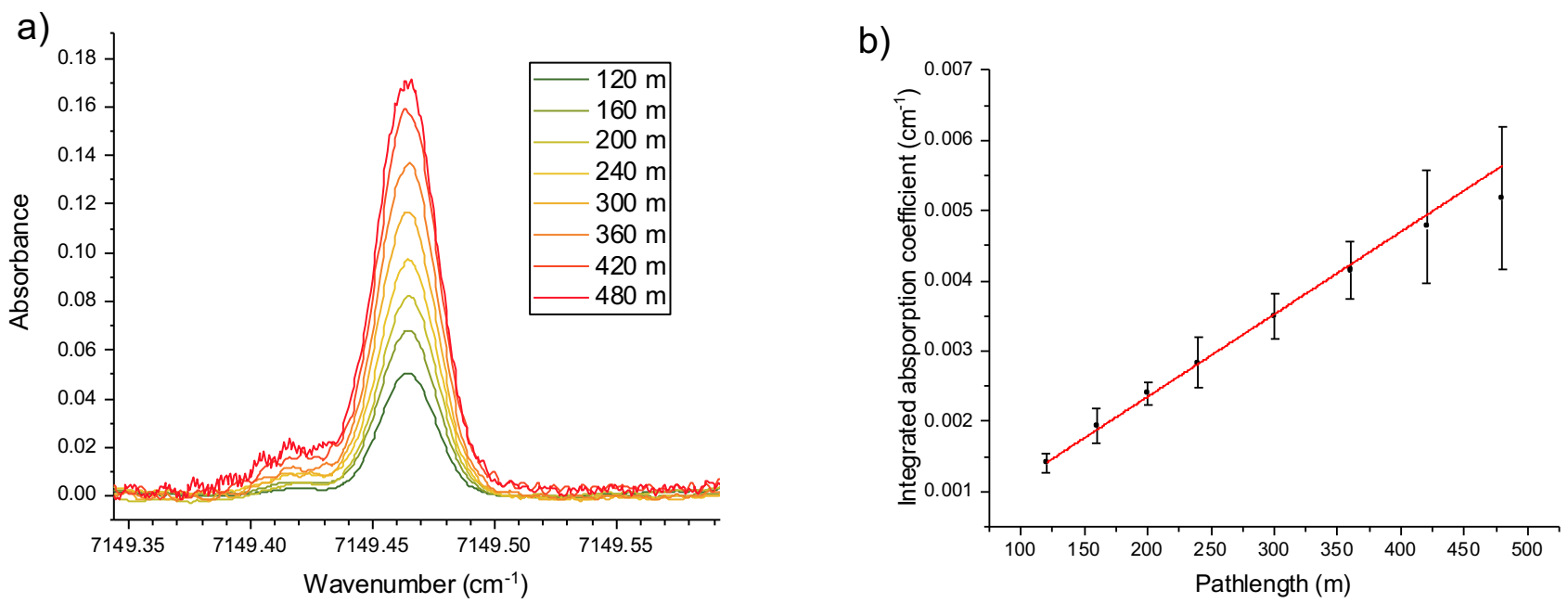

Figure 4. (a) Absorbance of the $\mathrm{R}(17)$ rovibrational line of $\mathrm{N}_{2} \mathrm{O}$ in the $(3,2,0,1) \leftarrow(0,0,0,0)$ vibrational band measured with the DL-1380-0050 IR source in the $7149.5 \mathrm{~cm}^{-1}$ region for 8 different path-lengths in MULTICHARME. The shoulder observed at low frequency is assigned to the DL source which is not perfectly monomode in this region. (b) Verification of the linearity of the integrated absorption coefficient with the pathlength. The error bars $(3 \sigma)$ are deduced from the gaussian fits.

The absorption linearity was first checked in the near-IR by probing the $\mathrm{R}(17)$ rovibrational transition of $\mathrm{N}_{2} \mathrm{O}$ in the highly excited $(3,2,0,1) \leftarrow(0,0,0,0)$ vibrational band. From the HITRAN database (Gordon et al. 2022), this line is predicted with a weak intensity $\left(\mathrm{S}=7.1 \times 10^{-25} \mathrm{~cm}^{-1} /\left(\right.\right.$ molecule. $\left.\left.\mathrm{cm}^{-2}\right)\right)$ and is expected at $7149.45 \mathrm{~cm}^{-1}$, where the DL-1380-0050 performs optimally. As shown in Fig. 4a, the near IR rovibrational absorbance has been obtained for 8 different paths in MULTICHARME covering interaction distances from $120 \mathrm{~m}$ to $480 \mathrm{~m}$ at a pressure of $20 \mathrm{mbar}$. In order to avoid any saturation of the absorption signal, a calibrated mixture of $\chi=1000$ ppmv of $\mathrm{N}_{2} \mathrm{O}$ diluted in $\mathrm{N}_{2}$ was used. In order to deduce the absorbance given by $A(v)=\ln \frac{I_{0}(v)}{I(v)}$, baseline variations $I_{0}(v)$ were measured systematically with the signal variations $I(v)$. The 235 wavenumber calibration was performed with the measurements of the WA-1500 wavelength-meter with an accuracy better 
than $4 \times 10^{-3} \mathrm{~cm}^{-1}$. The integrated absorption coefficients, in $\mathrm{cm}^{-1}$ units, are determined by fitting the Doppler broadened nearIR lines with gaussian profiles. They have been plotted in Fig. $4 \mathrm{~b}$ according to the associated pathlengths. A linear regression weighted with the error bars $(3 \sigma)$ deduced from the gaussian fits yields a $\mathrm{R}^{2}$ of 0.998 and a slope $\mathrm{s}=1.17(7) \times 10^{-5} \mathrm{~cm}^{-1} / \mathrm{m}^{\text {. The }}$ linearity observed ensures the absence of saturation and guarantees that the IR photons introduced into MULTICHARME have traveled the same optical path before they reach the detector (Kwabia Tchana, 2013). From the measured slope in Fig. 4b and the averaged linewidth estimated to $\Delta v=0.01 \mathrm{~cm}^{-1}$ (HWHM), we can deduce, according to the equation $\alpha_{0, \exp }=\frac{s}{\pi \Delta v}$, an experimental value of the maximal absorption coefficient of the line $\alpha_{0, \exp }=3.72 \times 10^{-6} \mathrm{~cm}^{-1}, 50$ times bigger than the expected value $\alpha_{0, t h}=7.26 \times 10^{-8} \mathrm{~cm}^{-1}$ given by the equation $\alpha_{0, t h}=\frac{s \chi}{k_{B} T \gamma_{a i r}}$ (Hindle et al. 2018) where the line intensity $\mathrm{S}$ and the air-broadening coefficient $\gamma_{a i r}$ are the tabulated values in the HITRAN database. The variation between $\alpha_{0, \exp }$ deduced from our measurements and $\alpha_{0, t h}$ could be partially explained by significant uncertainties of the tabulated near IR parameters $\mathrm{S}$ and $\gamma_{\text {air }}$ from a very weak rovibrational line which was, to the best of our knowledge, never measured before this study.
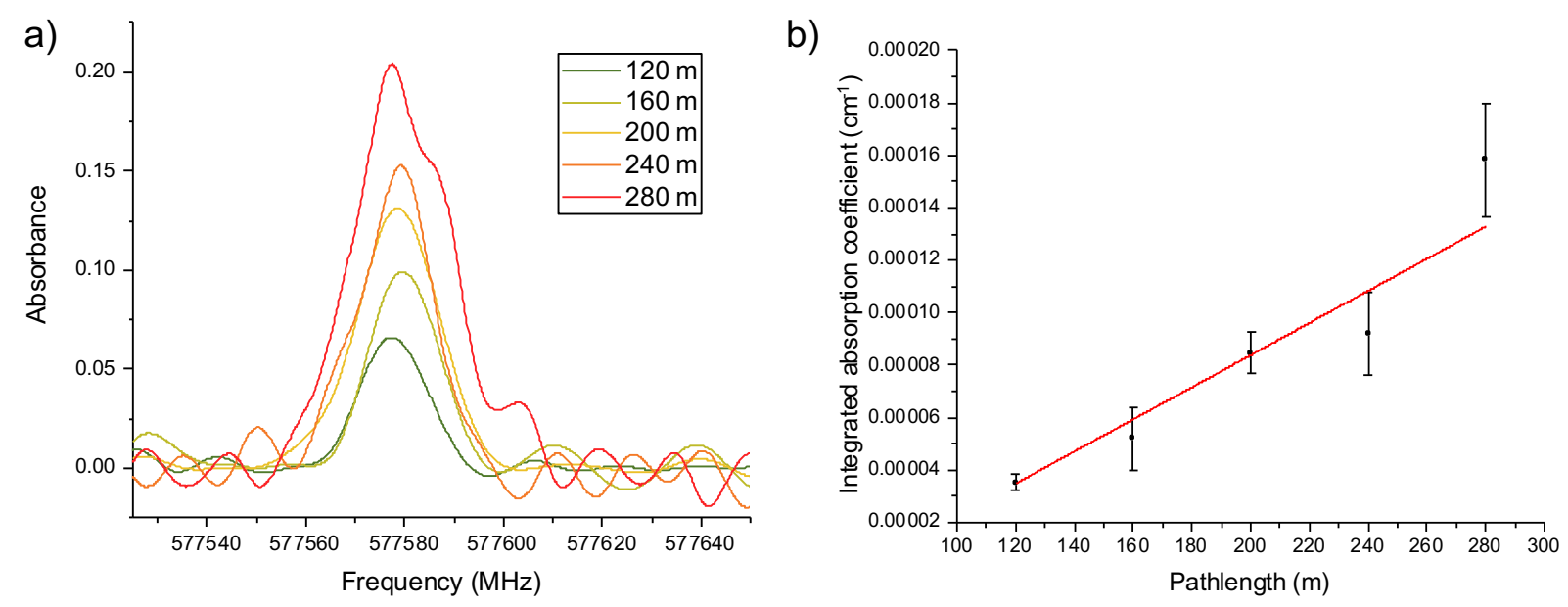

Figure 5. (a) Absorbance of the $\mathrm{R}(22)$ rotational line of $\mathrm{N}_{2} \mathrm{O}$ in its ground state measured with the AMC THz source in the $577.58 \mathrm{GHz}$ region for 6 different path-lengths in MULTICHARME. (b) Verification of the linearity of the integrated absorption coefficient with the path-length. The error bars $(3 \sigma)$ are deduced from the Voigt fits.

The absorption linearity was also checked in the $\mathrm{THz}$ domain by probing the pure $\mathrm{R}(22)$ rotational transition of $\mathrm{N}_{2} \mathrm{O}$ in its ground state expected at $577578.215 \mathrm{MHz}$ with a line intensity estimated to $\mathrm{S}=2.9 \times 10^{-22} \mathrm{~cm}^{-1} /\left(\right.$ molecule.cm $\left.\mathrm{cm}^{-2}\right), 400$ times stronger than the previously probed near-IR rovibrational line and experimentally measured. For the THz measurement, the mixing ratio in air was 400 ppmv and the rotational lines were measured at a total pressure of 4 mbar. Unlike IR rovibrational 
bands, with only few mbar of pressure, the collisional broadening is dominant compared to the Doppler one and a Voigt profile including both effects is required to fit the THz lines. The measured absorbances for five different pathlengths from $120 \mathrm{~m}$ to $280 \mathrm{~m}$ are presented in Fig. 5a. Compared to the IR lines, strong baseline oscillations due to standing THz waves affect the line profile especially for the longest $\mathrm{THz}$ paths. In Fig. 5b, we have determined the integrated absorption coefficients by integrating the rotational absorbance. Compared to the IR results, larger uncertainties are deduced from the integration process due to the baseline variations. Nevertheless a linear behavior is obtained with the different pathlengths at least up to $200 \mathrm{~m}$ which constitutes already a record for a THz radiation in a multi-pass cell (Cuisset et al. 2021). With $\mathrm{s}=6.1(7) \times 10^{-7} \mathrm{~cm}^{-1} / \mathrm{m}$, the slope obtained with the THz measurement is smaller than the IR one. An associated value of $\alpha_{0, \text { exp }}=5.71 \times 10^{-6} \mathrm{~cm}^{-1}$ is deduced from this slope and from the THz rotational linewidth estimated to $3.4 \times 10^{-4} \mathrm{~cm}^{-1}$ (HWHM), around 300 times smaller than the IR rovibrational linewidth highlighting the excellent selectivity of the THz spectroscopy compared to the IR one due to a weaker Doppler broadening. Unlike the near-IR results, the measured maximal absorption $\alpha_{0, \text { exp }}$ is in excellent agreement with the calculated value from the tabulated intensity $\mathrm{S}$ and the air-broadening coefficient $\gamma_{\text {air }}$ yielding to $\alpha_{0, t h}=$ $1.23 \times 10^{-5} \mathrm{~cm}^{-1}$. No doubt that in this case, the rotational parameters of $\mathrm{N}_{2} \mathrm{O}$ are more reliable and here the slight difference between the two values are due to an absorbance averaged on the full line profile compared to an absorption $\alpha_{0, t h}$ calculated for the maximum of the rotational line.

\subsection{Specificity of the THz measurements}

Compared to IR rovibrational spectroscopy, rotational $\mathrm{THz}$ spectroscopy presents several advantages and disadvantages for the monitoring of atmospheric compounds in an ASC such as CHARME.

The main advantage deals with the selectivity of the technique at low pressure. Indeed, $\mathrm{THz}$ rotational linewidths have two main contributions: the temperature dependent Doppler broadening and the pressure and temperature dependent collisional broadening. The first contribution is the residual source of broadening at low pressure (below $1 \mathrm{mbar}$ ), the associated linewidth never exceeds few $\mathrm{MHz}$ at $\mathrm{THz}$ frequencies giving rotational spectroscopy a much better selectivity than that obtained in IR gas phase rovibrational spectroscopy especially for the light stable and reactive polar atmospheric compounds (De Lucia, 2010). Moreover we have demonstrated, these last years, the ability of gas phase THz rotational spectroscopy to perform absolute quantification without any calibration step of targeted gaseous pollutants in complex chemical mixtures including both gases and particles (Bigourd et al., 2006; Bigourd et al., 2007; Mouret et al., 2013). Several measurements performed in realistic gas phase media contaminated with particles demonstrate that $\mathrm{THz}$ spectroscopy with submillimeter and mm-wavelengths is less sensitive to the scattering than shorter wavelength IR and UV radiations. Finally, thanks to the agility of the RF synthesizer driving the AMC THz source, the acquisition times (typically hundreds of ms) are rapid and a timeresolved quantification providing kinetic parameters is also possible and simplified by using the THz electronic sources (Omar et al., 2015). 
Despite these different advantages, some difficulties have to be underlined concerning THz monitoring of gas traces in ASCs: (i) first of all, the output power level of the THz sources compared to the optical IR one: as shown, in Fig.3, the THz measurements are performed at the $\mu \mathrm{W}$ level, at least two orders of magnitude lower than the power available in the near-IR measurements, that affects, inevitably, the sensitivity of the detection scheme; (ii) the price to pay for maintaining an excellent selectivity is to carry out measurements at low pressures representative of the pressure levels of the upper atmosphere and a selective detection of rotational lines at tropospheric pressures is difficult to imagine; (iii) Finally, optical pathlengths between 120 to $240 \mathrm{~m}$ produce standing waves with free spectral ranges (FSR) between $625 \mathrm{kHz}$ to $1.25 \mathrm{MHz}$ very close to the linewidths of the measured rotational absorptions. These standing waves strongly affect the baseline and the measured line profiles as observed in Fig. 4a. In Sect. 3.2, we demonstrate some possibilities offered by THz spectroscopic measurements in MULTICHARME taking into account the different advantages and disadvantages previously mentioned.

\subsubsection{Analysis of isotopic composition}

THz rotational spectroscopy is a powerful technique of detection at low pressure due to its great selectivity allowing to discriminate: (i) polar compounds in complex chemical mixture (Bigourd et al., 2006; Bigourd et al., 2007; Mouret et al., 2013); (ii) isomers and stable conformers amongst VOCs (Roucou et al. 2020, Roucou et al. 2018); (iii) isotopomers of small polar atmospheric compounds in natural abundance (Hindle et al., 2019). For this last point, it has been demonstrated that THz rotational spectroscopy is able to determine relative isotopic abundances of small polar compounds with accuracies of few $\%$ 305 (Lou et al., 2019). In order to highlight the selectivity of THz monitoring in MULTICHARME, we present in Fig.6 some measurements for four different isotopomers of pure $\mathrm{N}_{2} \mathrm{O}$, in natural abundance. Table 1 summarizes abundances, line frequencies and intensities tabulated in spectroscopic databases (Pickett et al. 1998, Gordon et al. 2022). For the four isotopomers, the differences between the observed and the JPL frequencies never exceed $500 \mathrm{kHz}$. In Fig. 6a, for each pathlength the absorption of the $\mathrm{R}(23)$ rotational transition of the most abundant ${ }^{14} \mathrm{~N}^{14} \mathrm{~N}^{16} \mathrm{O}$ isotopomer is saturated. Nevertheless the equivalent transition for the ${ }^{14} \mathrm{~N}^{15} \mathrm{~N}^{16} \mathrm{O}$ expected only $43 \mathrm{MHz}\left(1.4^{*} 10^{-3} \mathrm{~cm}^{-1}\right)$ lower in frequency with an intensity around 260 times weaker is clearly observed and resolved. The other monosubstituted isotopomers ${ }^{15} \mathrm{~N}^{14} \mathrm{~N}^{16} \mathrm{O}$ and ${ }^{14} \mathrm{~N}^{14} \mathrm{~N}^{18} \mathrm{O}$ are also observed with the shortest pathlength $\mathrm{L}=120 \mathrm{~m}$ at pressure close to 1 mbar (Fig. $6 \mathrm{~b}$ ). An isotopic ratio $\left[{ }^{15} \mathrm{~N}^{14} \mathrm{~N}^{16} \mathrm{O}\right] /\left[{ }^{14} \mathrm{~N}^{14} \mathrm{~N}^{18} \mathrm{O}\right]$ of 1.87 is deduced from the intensities of the two absorption lines plotted in Fig. 6b. This value is sufficiently close to the expected value of 1.83 deduced from the natural abundances in Table 1 to suggest the possibility to 315 use THz spectroscopy with MULTICHARME for the analysis of the isotopic composition of atmospheric trace gases and to detect anomalous isotopic signature, a powerful approach to identify sources and sinks of pollutants and/or greenhouse gases (Röckmann et al., 2001). 
a)

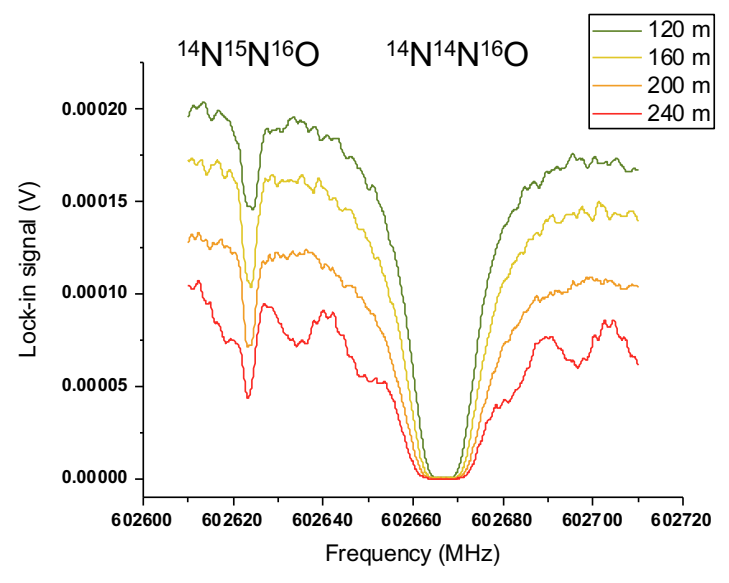

b)
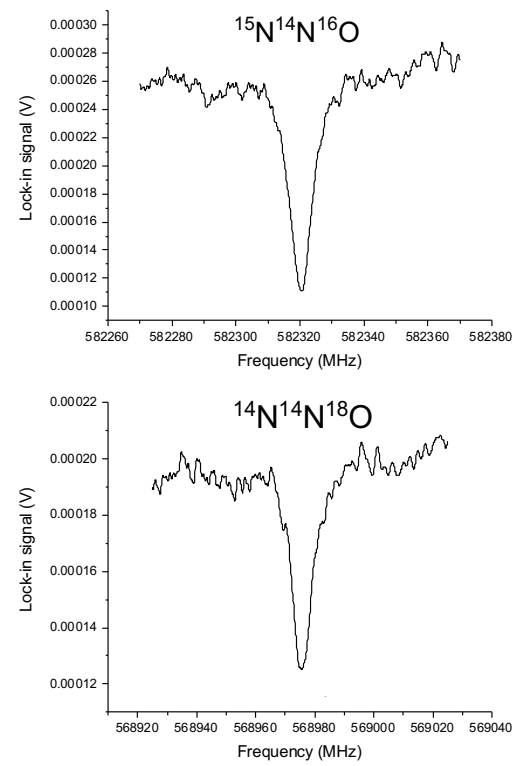

320 Figure 6. $\mathrm{THz}$ absorptions of four different $\mathrm{N}_{2} \mathrm{O}$ isotopomers in MULTICHARME measured without baseline treatment. (a) $\mathrm{R}$ (23) rotational transition measured at $\mathrm{P}=0.36$ mbar for the most abundant ${ }^{14} \mathrm{~N}^{14} \mathrm{~N}^{16} \mathrm{O}$ and the less abundant ${ }^{14} \mathrm{~N}^{15} \mathrm{~N}^{16} \mathrm{O}$ isotopomers; measurements are performed for four optical pathlengths between $120 \mathrm{~m}$ to $240 \mathrm{~m}$ (in each case the ${ }^{14} \mathrm{~N}^{14} \mathrm{~N}^{16} \mathrm{O}$ absorption is saturated). (b) Measurements at $\mathrm{P} \sim 1 \mathrm{mbar}$ and $\mathrm{L}=120 \mathrm{~m}$, lower in frequency, of the same rotational transition for the ${ }^{15} \mathrm{~N}^{14} \mathrm{~N}^{16} \mathrm{O}$ and ${ }^{14} \mathrm{~N}^{14} \mathrm{~N}^{18} \mathrm{O}$ isotopomers.

Table 1. Natural abundances of the four most abundant isotopomers of $\mathrm{N}_{2} \mathrm{O}$ (Gordon et al. 2022). Tabulated line intensity and frequency of the $\mathrm{R}(23)$ rotational transition, respectively from the JPL (Pickett et al. 1998) and the HITRAN (Gordon et al. 2022) database. Difference between tabulated and measured frequencies in Fig. 6.

\begin{tabular}{lllll}
\hline Isotopomer & $\begin{array}{l}\text { Natural Abundance } \\
\mathbf{\%}\end{array}$ & $\begin{array}{l}\text { Line intensity } \\
\mathbf{c m}^{-1} /(\mathbf{m o l e c u l e . c m}\end{array}$ & $\begin{array}{l}\text { Line Frequency } \\
\mathbf{( M H z})\end{array}$ & $\begin{array}{l}\text { obs - calc } \\
(\mathbf{M H z})\end{array}$ \\
\hline${ }^{14} \mathbf{N}^{14} \mathbf{N}^{16} \mathbf{O}$ & 99.0333 & $2.9^{*} 10^{-22}$ & 602666.49 & 0.41 \\
${ }^{14} \mathbf{N}^{15} \mathbf{N}^{16} \mathbf{O}$ & 0.3641 & $1.11^{*} 10^{-24}$ & 602623.41 & 0.06 \\
${ }^{15} \mathbf{N}^{14} \mathbf{N}^{16} \mathbf{O}$ & 0.3641 & $1.05^{*} 10^{-24}$ & 582320.00 & 0.45 \\
${ }^{14} \mathbf{N}^{14} \mathbf{N}^{18} \mathbf{O}$ & 0.1986 & $5.22^{*} 10^{-25}$ & 568975.30 & 0.25 \\
\hline
\end{tabular}

3.2.2 Absolute quantification of stable and reactive atmospheric traces

A priori all the polar compounds may be detected and quantified from their rotational signatures. In practice, for THz atmospheric monitoring at trace levels, we must opt for the lighter and the more strongly polar compounds with intense and 
resolved rotational transitions generally listed in the international databases. For these molecules, rotational line frequencies, line widths and line intensities are known with a good degree of accuracy allowing, if the line profile is preserved during the measurement, an absolute quantification without any standard of calibration. In the present article, we demonstrate this statement in Fig. 7a by fitting the integrated intensity of the $\mathrm{R}(22)$ rotational line of $\mathrm{N}_{2} \mathrm{O}$ diluted in $\mathrm{N}_{2}$ at 1000 ppmv. Prior to the fit, two baseline treatments have be done in order to reduce the oscillations due to standing waves occurring in MULTICHARME: first of all, thanks to the agility of the RF synthesizer, we have applied simultaneously to the amplitude modulation (AM) a rapid frequency modulation (FM) with a depth exceeding the FSR of the interaction length allowing a partial minimization of the effects of the standing waves. Next, during the post treatment of the recorded signal leading to the absorbances shown in Fig. 7, a FFT filter was used to eliminate as much as possible the rapid oscillations of the baseline. The concentration " $\mathrm{N}$ " of absorbing $\mathrm{N}_{2} \mathrm{O}$ molecules in molec. $\mathrm{cm}^{-3}$ is directly deduced from the relation: $N=\frac{\int A(v) d v}{S \times L}$ with the integrated absorption coefficient $\int A(v) d v$ in $\mathrm{cm}^{-1}$ determined with a Voigt fit, the line intensity $S$ in $\mathrm{cm}^{-1} /\left(\mathrm{molec}_{\mathrm{cm}}{ }^{-2}\right)$ tabulated in HITRAN (Gordon et al. 2022) and the pathlength $L$ in cm. Finally the mixing ratio $\chi$ is deduced by: $\chi=\frac{N}{P} k_{B} T$ with $\mathrm{P}$ and $\mathrm{T}$, the pressure and the temperature in CHARME during the measurement.
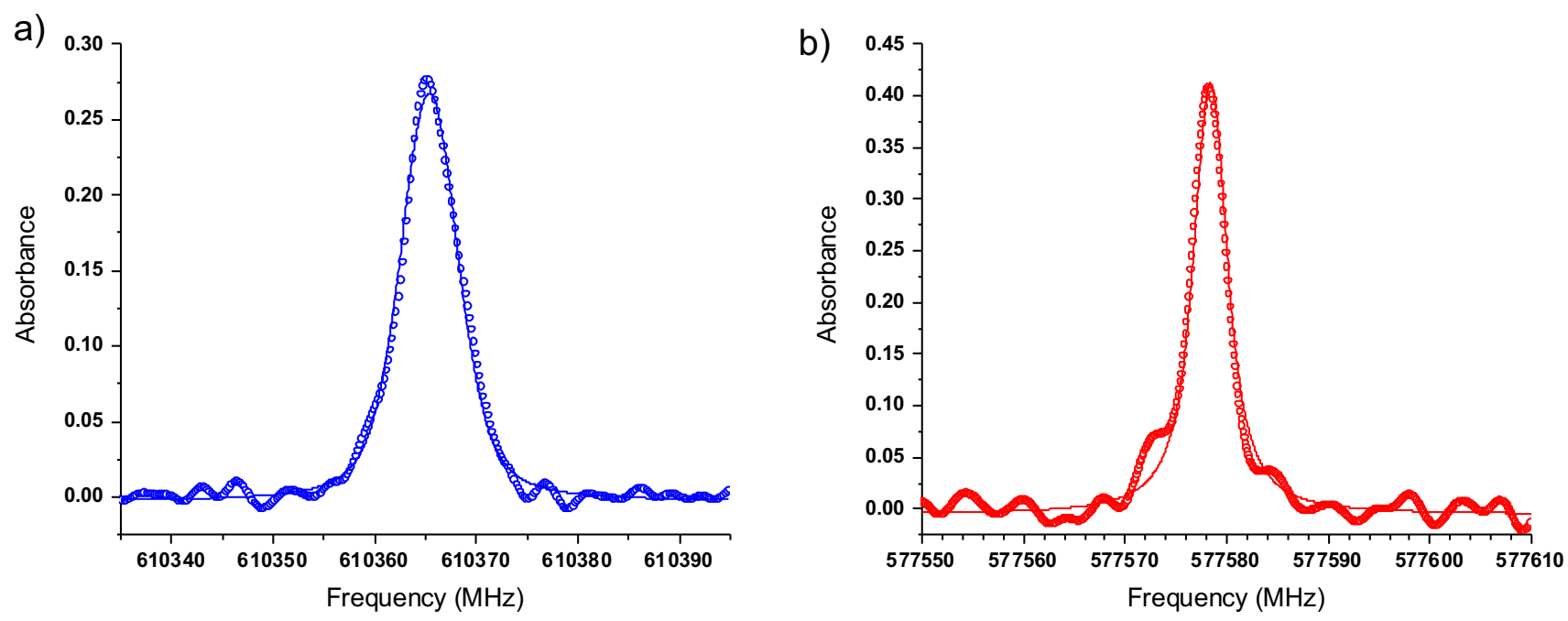

Figure 7. THz trace gas quantification of stable $\mathrm{N}_{2} \mathrm{O}$ and reactive $\mathrm{O}_{3}$ in MULTICHARME. (a) red circles: $\mathrm{R}(22)$ transition of 1000 ppmv $\mathrm{N}_{2} \mathrm{O}$ diluted in $\mathrm{N}_{2}$ measured at $\mathrm{P}=0.5$ mbar (AM: $\mathrm{f}_{\bmod }=4.5 \mathrm{kHz}+\mathrm{FM}$ : $\mathrm{f}_{\bmod }=50 \mathrm{kHz} \omega_{\text {depth }}=1.44 \mathrm{MHz}$ ); red solid line: Fit with a Voigt profile $\left(\int A(v) d v=2.4(3) \mathrm{MHz} ; v=577578,36 \mathrm{MHz}\right)$. (b) blue circles: $25_{1,25} \leftarrow 24_{0,24}$ transition of an unknown quantity of $\mathrm{O}_{3}$ diluted in air produced by an ozone generator measured at $\mathrm{P}=1.5 \mathrm{mbar}\left(\mathrm{AM}\right.$ : $\mathrm{f}_{\mathrm{mod}}=4.5 \mathrm{kHz}+\mathrm{FM}$ : $\left.\mathrm{f}_{\mathrm{mod}}=50 \mathrm{kHz} \omega_{\text {depth }}=1.08 \mathrm{MHz}\right)$; blue solid line: Fit with a Voigt profile $\left(\int A(v) d v=2.3(2) \mathrm{MHz} ; v=610365,35 \mathrm{MHz}\right)$ 
In Fig. 7a, an integrated absorption of $2.4 \pm 0.3 \mathrm{MHz}$ was fitted giving a $\mathrm{N}_{2} \mathrm{O}$ concentration of $\mathrm{N}=(1.4 \pm 0.2) * 10^{13} \mathrm{molec}^{-\mathrm{cm}^{-3}}$ and a mixing ratio $1140 \pm 160 \mathrm{ppmv}$. Taking into account the fit uncertainty mainly due to the baseline remaining oscillations, the absolute quantification procedure provides the level of dilution stipulated in the calibrated gas. Based on the previous method, an another example is given in Fig. $7 \mathrm{~b}$ with the quantification of an unknown quantity of ozone in CHARME. Ozone is a key compound in atmospheric chemistry, both in the troposphere and stratosphere (Finlayson-Pitts and Pitts, 2000) and a real time in situ monitoring of reactive ozone is very interesting for numerous ozonolysis reactions occurring in our atmosphere especially with VOCs. In our study, ozone was produced at atmospheric pressure by a generator (Air Tree Ozone Technology C-L010-DTI) which converts $\mathrm{O}_{2}$ into $\mathrm{O}_{3}$ from zero air exposed to a high voltage corona discharge. A unknown quantity of ozone was introduced at atmospheric pressure into CHARME. According to the injection time, This last one was estimated to around $500 \mathrm{ppm}$ from the injection time and a calibration with an $\mathrm{O}_{3}$ photometric analyzer. Then the ASC was pumped up to $1.5 \mathrm{mbar}$ and the $\mathrm{THz}$ spectrometer was used to detect and quantify $\mathrm{O}_{3}$ traces from individual rotational transitions. Ozone is

365 an asymmetric rotor with a large number of rotational transitions in the $\mathrm{THz}$ domain and its rotational frequencies and

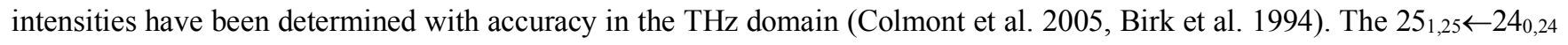
transition centered around $610 \mathrm{GHz}$ with a tabulated intensity of $\mathrm{S}=4.035^{*} 10^{-22} \mathrm{~cm}^{-1} /\left(\right.$ molec. $\left.\mathrm{cm}^{-2}\right)$ has been targeted. A mixing ratio of $258 \pm 22 \mathrm{ppmv}$ was deduced from the fit of the line with a Voigt profile presented in Fig. $7 \mathrm{~b}$. This value is around two times lower than the initial concentration injected in the ASC at atmospheric pressure. This difference is due to the losses on the chamber walls during the ozone injection and the pumping times from atmospheric pressure to few mbar. In Sect. 3.2.3, we show how to characterize at low pressure the kinetics of the $\mathrm{O}_{3}$ losses on the CHARME walls by THz monitoring.

\subsubsection{THz monitoring of the ozone decay in CHARME}

In Fig. 8, we demonstrate the ability of the THz source coupled to MULTICHARME to monitor at low pressure the ozone reactivity into CHARME. In this aim, the same $\mathrm{O}_{3} 25_{1,25} \leftarrow 24_{0,24}$ rotational transition centered at $610365,35 \mathrm{MHz}$ was targeted and measured during 12 hours over a frequency range of $60 \mathrm{MHz}$ each 3 minutes allowing to collect 240 absorbance spectra where their time evolution as a 3D plot is shown in Fig 8a. For each spectra, we have reproduced the baseline treatment and the line profile fit described in Fig. 7b. Then the data treatment to obtain the 240 absorbances of Fig. 8a and the 240 concentrations of Fig. $8 \mathrm{~b}$ has been batch processed with the Origin Software. As shown in Fig. 8b, the ozone concentration decrease exponentially from 230 ppmv to 15 ppmv in 12 hours. We have considered the first-order kinetic of the ozone decay due mainly due to the losses on the walls chamber. The concentration decrease was fitted using the exponential law $\left[O_{3}\right]_{t}=$ $\left[O_{3}\right]_{0} e^{-t / \tau_{O_{3}}}$ and a lifetime $\tau_{O_{3}}$ of $3.4 \pm 0.1 \mathrm{~h}$ was deduced from a fit weighted on the estimation of the limit of detection corresponding to the concentration associated to a $\mathrm{S} / \mathrm{N}$ ratio equal to 1 with $\mathrm{S}$, the maximal amplitude of the absorbance and

$385 \mathrm{~N}$, the maximal amplitude of the baseline oscillations. In the present case, we can see that for ozone concentrations lower than $50 \mathrm{ppm}$, we are very close to this limit. 
a)

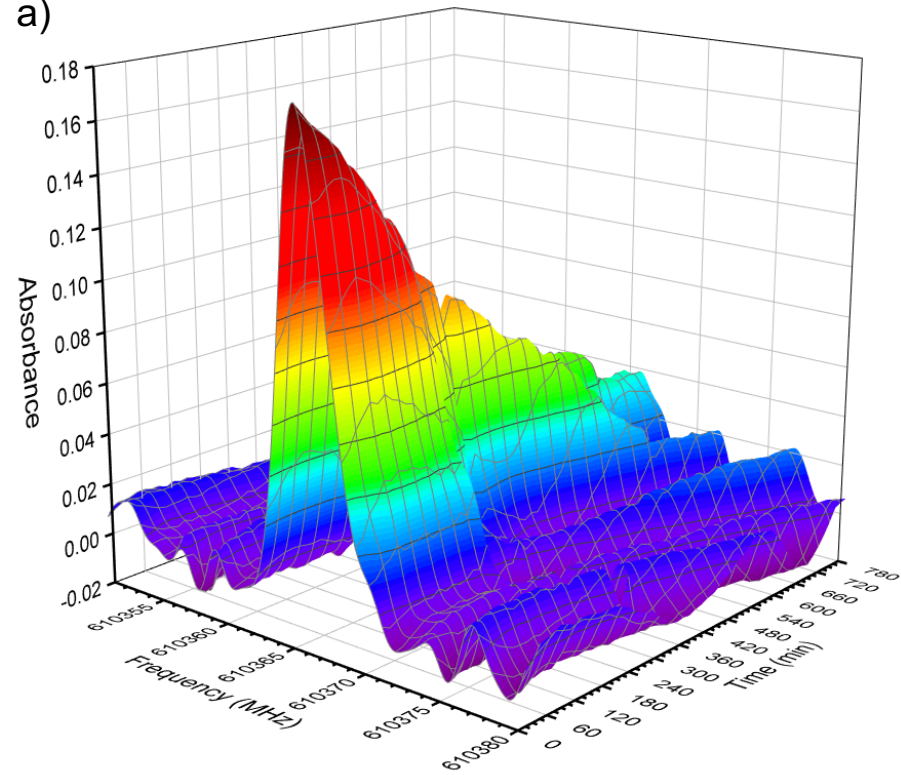

b)

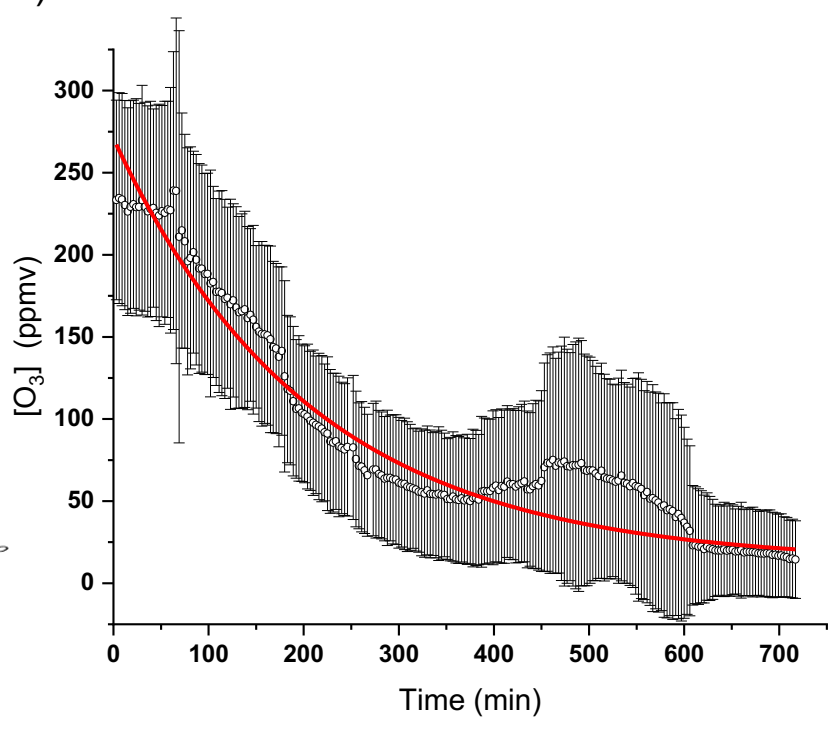

Fig. 8: THz monitoring of the ozone decay in CHARME measured during $12 \mathrm{~h}$ at $\mathrm{P}=1.1$ mbar. Fig. 8a: 3D plot gathering 240 absorbance spectra of the $\mathrm{O}_{3} 25_{1,25} \leftarrow 24_{0,24}$ rotational transition centered at $610365,35 \mathrm{MHz}$ vs time in min. Fig. 8b: Firstorder exponential fit of the ozone concentration decay in CHARME deduced by batch processing of the absorbance area shown in 8a. A lifetime $\tau_{O_{3}}$ of $3.4 \pm 0.1 \mathrm{~h}$ is deduced from the fit weighted on the LODs.

The losses of ozone in CHARME have already been investigated at atmospheric pressure with an UV-photometric analyzer (Thermo Scientific 49i; $\lambda=254 \mathrm{~nm}$ ). Using several initial concentrations, from 0.7 to $4.8 \mathrm{ppmv}$, the $\mathrm{O}_{3}$ lifetimes $\tau_{O_{3}}$ were deduced from the first-order kinetics $\mathrm{O}_{3}$ walls loss reactions and varied from 6.2 to $13.8 \mathrm{~h}$ (Fayad et al. 2019) depending on the cleaning state of the chamber walls which can change for different initial concentrations of ozone. Compared to the previous measurements performed in CHARME with UV photometry analyzer, a shorter lifetime was determined by our low pressure $\mathrm{THz}$ measurements. Itoh et al. have developed and experimentally verified a physical model allowing to understand the pressure and the wall material dependences of the ozone walls loss rate in a cylindrical tube (Itoh et al. 2011; Itoh et al. 2004). They show that the variation of the ozone lifetime with the pressure due to wall losses can be reproduced by the equation (1):

$$
\frac{1}{\tau_{O_{3}}} \sim \frac{D_{e}}{P} f(a, l, \beta)+k N P
$$

where $P$ is the pressure, $N$ is the molecular density, $f(a, l, \beta)$ is a function depending on geometrical and surface properties of the chamber ( $a$ and $l$ are the radius and the length of the cylinder, respectively and $\beta$ is a surface parameter (Itoh et al. 405 2011)), $D_{e}$ is an equivalent diffusion coefficient giving the magnitude of the surface loss rate of ozone according to the material and $k$ is a loss rate coefficient due to collisions with oxygen. Under our conditions with the ozone generated directly in 
CHARME at atmospheric pressure, the ozone loses are mainly due to the surface losses, corresponding to the first term of Eq. (1) and, therefore, as it is shown by our results, a decrease of the lifetime at low pressure was expected due to the reinforcement of the losses by the ozone diffusion on the walls chamber.

\section{Conclusions}

We have developed for the Dunkirk ASC CHARME a Chernin-type multi-pass cell allowing to perform spectroscopic measurements over approximately three decades of frequencies from the submillimetre-wave spectral domain to the near-IR. In this study, the performances of MULTICHARME have been characterized in the near-IR using a diode laser source oscillating around $1.4 \mu \mathrm{m}$ and in the $\mathrm{THz}$ around $600 \mathrm{GHz}$ with a compact and versatile AMC. Benefiting from a base dimension of $5 \mathrm{~m}$, MULTICHARME allows to reach very long optical paths for absorption spectroscopy from $120 \mathrm{~m}$ to 280 $\mathrm{m}$ in the THz domain and to $540 \mathrm{~m}$ in the IR. The output powers have been measured for the different pathlengths and an effective mirror reflectivity better than $94 \%$ has been measured both in the $\mathrm{THz}$ and in the near-IR. By targeting rovibrational and rotational transitions of the $\mathrm{N}_{2} \mathrm{O}$ greenhouse gas, the linearity of the integrated absorption coefficients has been checked and experimental values of the maximal absorption coefficient were deduced and compared to the expected values deduced from the tabulated spectroscopic parameters. The THz monitoring of atmospheric compounds presents some specificities in comparison with other spectroscopic techniques: As example, the measurements of the rotational lines of the most abundant isotopomers of $\mathrm{N}_{2} \mathrm{O}$ highlight the exceptional selectivity of the technique which should be able to detect anomalous isotopic fractionation. Moreover the rotational absorbance allows an absolute quantification of the absorbing compound without standard of calibration. The demonstration was performed on stable $\mathrm{N}_{2} \mathrm{O}$ and reactive $\mathrm{O}_{3}$ greenhouse gases. According to the measured $\mathrm{S} / \mathrm{N}$ ratio, the reached detection thresholds are limited to few tens of ppmv due to the baseline oscillations involved by numerous standing waves occurring in MULTICHARME. A work is under progress to characterize how these standing waves affect the $\mathrm{THz}$ detected signal in the modified Chernin cell and to study the possibility to correctly model the $\mathrm{THz}$ baseline oscillations, a required step for the improvement of the LODs. Finally, THz monitoring has been used to quantify, at low pressure, the decay of ozone into CHARME. The ozone lifetime of $3.4 \pm 0.1 \mathrm{~h}$ deduced at low pressure in the chamber by $\mathrm{THz}$ spectroscopy is shorter than those obtained in previous measurements at atmospheric pressure using a UV photometry analyzer. At low pressure, the ozone losses by diffusion on the ASC are accentuated.

This work demonstrates that THz monitoring is able to quantify gaseous compounds in an ASC such CHARME, and will allow the determination of kinetic rate coefficients as well as reactional pathways for targeted atmospheric processes. In the future, we plan to couple a Fourier Transform interferometer to MULTICHARME allowing to study the tropospheric reactivity of VOCs at middle resolution $\left(0.5 \mathrm{~cm}^{-1}\right)$ using vibrational spectroscopy on a broadband spectral range from the far to the near-IR domains $\left(20 \mathrm{~cm}^{-1}-8000 \mathrm{~cm}^{-1}\right)$. Moreover, THz high resolution rotational spectroscopy will be used in CHARME for the study of the stratospheric processes at low pressures (few mbars) and low temperatures ( $\mathrm{T}<-20^{\circ} \mathrm{C}$ obtained by cryocooling). In particular the chemistry of stable and unstable halogenated species involved in the catalytic destruction of 
https://doi.org/10.5194/amt-2021-399

Preprint. Discussion started: 1 December 2021

(c) Author(s) 2021. CC BY 4.0 License.

(c) (i)
Atmospheric

Measurement

Techniques

Discussions

and unstable $\mathrm{OX}(\mathrm{X}=\mathrm{F}, \mathrm{Cl}, \mathrm{Br}, \mathrm{I})$ compounds lie in the $\mathrm{THz}$ domain and are sufficiently intense for their monitoring at trace levels (Pickett et al., 1998).

Data availability: Data are available upon request to the corresponding author

Supplement. Figures S1, S2, S3 and S4 are available online at:

Author contributions. AC was involved with the supervision and conceptualization. JD, EF, PK, WZ, BF and AC contribute to the conception of MULTICHARME. The measurements in CHARME were performed by: JD, EF, JB, NH, FH and AC. $\mathrm{JD}, \mathrm{JB}, \mathrm{RB}, \mathrm{GD}$ and $\mathrm{AC}$ contribute to the data curation. AC wrote the manuscript with some contributions of JD, FH, $\mathrm{NH}$ and CC. The figures were plotted by JD, JB, PK, BF and AC. All the authors contributed to the paper discussion and revision. AC, EF, GM and CC were involved in the funding acquisition. The LPCA towards CHARME is an associated partner of the ATMO-ACCESS European facility.

455 Competing interests. The authors declare that they have no conflict of interest

Acknowledgements. We are grateful to the logistics department of the Dunkirk University Management Center for their help in installing the MULTICHARME flanges. Marc Fourmentin is also thanked for its help in the graphical abstract conception.

460 Financial Support. This work was supported by the CaPPA project (Chemical and Physical Properties of the Atmosphere) funded by the French National Research Agency (ANR-11-LABX-0005-01) and the CLIMIBIO program supported by the Hauts-de-France Regional Council, the French Ministry of Higher Education and Research and the European Regional Development Fund. J.D. and J.B were funded respectively by CLIMIBIO and the Pôle Métropolitain de la Côte d'Opale. MULTICHARME was founded by the Research Quality Bonus of the University of Littoral Côte d'Opale, the Optics, Photonics, Applications Lasers (OPAL) network and the IRenE program.

\section{References}

Bigourd, D. ; Cuisset, A. ; Hindle, F. ; Matton, S.; Bocquet R.; Mouret, G.; Cazier, F.; Dewaele, D. ; Nouali, H. : Multiple component analysis of cigarette smoke using THz spectroscopy, comparison with standard chemical analytical methods. Appl. Phys. B 86, 579-585, 2007. 
https://doi.org/10.5194/amt-2021-399

Preprint. Discussion started: 1 December 2021

(c) Author(s) 2021. CC BY 4.0 License.

(c) (P)
Atmospheric

Measurement

Techniques

Discussions

Bigourd, D. ; Cuisset, A. ; Hindle, F. ; Matton, S.; Fertein, E. ; Bocquet R.; Mouret, G. : Detection and quantification of multiple molecular species in mainstream cigarette smoke by continuous-wave terahertz spectroscopy. Opt. Lett. 31(15), 2356$2358,2006$.

Birk, M.; Wagner, G.; Flaud, J. M.: Experimental Line strengths of Far-Infrared Pure Rotational Transitions of Ozone. J. Mol. Spectrosc., 163(1), 245-261, (1994)

Bloss, C.; Wagner, V.; Bonzanini, A. ; Jenkin, M. E. ; Wirtz, K.; Martin-Reviejo, M.; Pilling, M. J.: Evaluation of detailed aromatic mechanisms (MCMv3 and MCMv3.1) against environmental chamber data, Atmos. Chem. Phys. 5, 623-639, 2005 480 a.

Bloss, C.; Wagner, V.; Jenkin, M. E.; Volkamer, R.; Bloss, W. J.; Lee, J. D.; Heard, D. E.; Wirtz, K ; Martin-Reviejo, M.; Rea, G.; Wenger, J. C.; Pilling, M. J. Development of a detailed chemical mechanism (MCMv3.1) for the atmospheric oxidation of aromatic hydrocarbons, Atmos. Chem. Phys. 5, 641-664, 2005 b.

Branes, I., Becker, K. H., Mihalopoulos, N.: An FTIR Product Study of the Photooxidation of Dimethyl Disulfide.

J. Atmos. Chem. 18, 267-289, doi: 10.1007/BF00696783, 1994.

Brubach, J.-B.; Manceron, L.; Rouzières, M.; Pirali, O.; Balcon, D.; Tchana, F.; Boudon, V.; Tudorie, M.; Huet, T.; Cuisset, 490 A.; et al. Performance of the AILES THz-infrared beamline on SOLEIL for high resolution spectroscopy. AIP Conf. Proc. 1214, 81-84, 2010.

Chernin, S. M.: Promising Version of the three-objective multipass matrix system, Opt. Express, 10, 104-107, doi: 10.1364/OE.10.000104, 2002.

495

Clerbaux, C.; Boynard, A.; Clarisse, L.; George, M.; Hadji-Lazaro, J.; Herbin, H.; Hurtmans, D.; Pommier, M.; Razavi, A.; Turquety, S.; et al. Monitoring of atmospheric composition using the thermal infrared IASI/MetOp sounder. Atmos. Chem. Phys., 9, 6041-6054, 2009.

500 Colmont, J. M.; Bakri, B.; Demaison, J.; Mäder, H.; Willaert, F.; Tyuterev, V. G.; Barbe, A.: Microwave Fourier transform, millimeterwave, and submillimeterwave spectra of ozone in its vibrational ground state. J. Mol. Spectrosc., 233(2), 293-296, 2005. 
https://doi.org/10.5194/amt-2021-399

Preprint. Discussion started: 1 December 2021

(c) Author(s) 2021. CC BY 4.0 License.
Atmospheric

Measurement

Techniques

Discussions

Cuisset, A.; Hindle, F.; Mouret, G.; Bocquet, R.; Bruckhuisen, J.; Decker, J.; Pienkina, A.; Bray, C.; Fertein, É.; Boudon, V. :

505 Terahertz Rotational Spectroscopy of Greenhouse Gases Using Long Interaction Path-Lengths. Appl. Sci., 11, 1229, doi:10.3390/app11031229, 2020.

De Lucia, F. C.: The submillimeter: A spectroscopist's view. J. Mol. Spectrosc., 261, 1-17, (2010).

EUROCHAMP 2020: https://www.eurochamp.org, last access : August 18, 2021.

Fayad, L.: Characterization of the new atmospheric simulation chamber CHARME, and study of the ozonolysis reaction of a biogenic VOC, the $\gamma$-terpinene. Thesis in Earth Sciences. Université du Littoral Côte d'Opale, English, NNT : 2019DUNK0550 . tel-03030246, 2019.

Finlayson-Pitts, B. J. and Pitts Jr, J. N.: Chemistry of the Upper and Lower Atmosphere Theory, Experiments, and Applications. Book. Academic Press, 2000.

Glowacki, D. R., Goddard, A., Hemavibool, K., Malkin, T. L., Commane, R., Anderson, F., Bloss, B. J., Heard, D. E., Ingham, 520 T., Pilling, M. J. and Seakins, P. W.: Design of and initial results from a Highly Instrumented Reactor for Atmospheric Chemistry (HIRAC). Atmos. Chem. Phys., 7, 5371-5390, doi: 10.5194/acp-7-5371-2007, 2007.

Gordon, I.E, Rothman, L.S., Hargreaves R.J. et al., "The HITRAN2020 molecular spectroscopic database", Journal of Quantitative Spectroscopy and Radiative Transfer 277, 107949, 2022.

Hindle, F.; Bocquet, R.; Pienkina, A.; Cuisset, A.; Mouret, G.: Terahertz gas phase spectroscopy using a high-finesse FabryPérot cavity. Optica, 6, 1449-1454, doi:10.1364/OPTICA.6.001449, 2019.

Hindle, F.; Kuuliala, L.; Mouelhi, M.; Cuisset, A.; Bray, C.; Vanwolleghem, M.; Devlieghere, F.; Mouret, G. and Bocquet, R.: Monitoring of food spoilage by high resolution THz analysis. Analyst, 143, 5536-5544, DOI: 10.1039/c8an01180j, 2018.

Itoh, H.; Rusinov, I. M.; Suzuki, T. and Suzuki, S.: Investigation of Ozone Loss Rate Influenced by the Surface Material of a Discharge Chamber. Ozone Sci. Eng., 26, 487-497, 2004.

535 Itoh, H.; Isegame, S.; Miura, H.; Suzuki, S. and Rusinov, I. M.: Surface Loss Rate of Ozone in a Cylindrical Tube . Ozone Sci. Eng., 33:2, 106-113, DOI: 10.1080/01919512.2011.548295, 2011. 
Kwabia Tchana, F., Willaert, F., Landsheere, X., Flaud, J. M., Lago, L., Chapuis, M., Herbeaux, C., Roy, P. and Manceron, L.: A new, low temperature long-pass cell for mid-infrared to terahertz spectroscopy and synchrotron radiation use. Rev. Sci. Instrum., 84, 093101, doi:10.1063/1.4819066, 2013.

Lou, M.; Dayne, F. S.; Gottheim, S.; Phillips, D. J.; Simmons, J. G.; Halas, N. J.; Everitt, H. O.: Quantitative analysis of gas phase molecular constituents using frequency- modulated rotational spectroscopy. Rev. Sci. Instrum., 90, 053110, doi:10.1063/1.5093912, 2019.

Massabò, D.; Danelli, S. G.; Brotto, P.; Comite, A.; Costa, C.; Di Cesare, A. ; Doussin, J.-F.; Ferraro, F. ; Formenti, P.; Gatta, E.; Negretti, L.; Oliva, M.; Parodi, F.; Vezzulli, L.; Prati, P. ChAMBRe: a new atmospheric simulation Chamber for Aerosol Modelling and Bio-aerosol Research. Atmos. Meas. Tech., 11, 5885-5900, 2018.

Meng, L., Coeur, C., Fayad, L., Houzel, N., Genevray, P., Bouzidi, H., Tomas, A. and Chen, W.: Incoherent broadband cavity enhanced absorption spectroscopy (IBBCEAS)-based strategy for direct measurement of aerosol extinction in a lidar blind zone. Opt. Lett., 45(7), 1611, doi: 10.1364/OL.389093, 2020.

Mouret, G., Guinet, M., Cuisset, A., Croizé, L., Eliet, S., Bocquet, R. and Hindle, F. : Versatile Sub-THz Spectrometer for Trace Gas Analysis. IEEE Sensors J., 13(1), 133-138, doi: 10.1109/JSEN.2012.2227055, 2013.

Omar, A.; Eliet, S.; Cuisset, A.; Dhont, G.; Cœur-Tourneur, C.; Bocquet, R.; Mouret, G.; Hindle, F.: Continuous monitoring of formaldehyde photolysis products by THz spectroscopy. Sensors; 12087, 1-7, 2015.

Pickett, H. M.; Poynter, R. L.; Cohen, E. A.; Delitsky, M. L.; Pearson, J. C. and Muller, H. S. P.: Submillimeter, Millimeter, and Microwave Spectral Line Catalog. J. Quant. Spectrosc. \& Rad. Transfer 60, 883-890, 1998.

Ravishankara, A. R.; Daniel, J. S.; Portmann, R. W.: Nitrous Oxide ( $\left.\mathrm{N}_{2} \mathrm{O}\right)$ : The Dominant Ozone-Depleting Substance Emitted in the 21st Century. Science 326(5949), 123-125, 2009. DOI: 10.1126/science.1176985

Ren, Y. PhD Thesis, University of Orleans, May 2017 a (http://www.icare.cnrs-orleans.fr/IMG/theses/2017-Ren-th.pdf).

Ren, Y.; Grosselin, B.; Daele, V.; Mellouki, A. Investigation of the reaction of ozone with isoprene, methacrolein and methyl vinyl ketone using the HELIOS chamber, Faraday Discuss., , 200, 289, 2017 b. 
https://doi.org/10.5194/amt-2021-399

Preprint. Discussion started: 1 December 2021

(C) Author(s) 2021. CC BY 4.0 License.

(c) (P)

\section{Atmospheric \\ Measurement \\ Techniques \\ Discussions}

Röckmann, T.; Kaiser, J.; Crowley, J. N.; Brenninkmeijer, C. A. N.; Crutzen, P. J.: The origin of the anomalous or "massindependent" oxygen isotope fractionation in tropospheric $\mathrm{N}_{2} \mathrm{O}$. Geophys. Res. Lett.; 28(3), 503-506, 2001.

Rohrer, F.; Bohn, B.; Brauers, T.; Brüning, D.; Johnen, F.-J.; Wahner, A.; Kleffmann, J. Characterisation of the photolytic

HONO-source in the atmosphere simulation chamber SAPHIR. Atmos. Chem. Phys. 5, 2189-2201, 2005.

Roucou, A.; Goubet, M.; Kleiner, I.; Bteich, S.; Cuisset, A.: Large Amplitude Torsions in Nitrotoluene Isomers Studied by Rotational Spectroscopy and Quantum Chemistry Calculations. CHEMPHYSCHEM; 21, 1 - 17, 2020.

580 Roucou, A.; Fontanari, D.; Dhont, G.; Jabri, A.; Bray, C.; Hindle, F.; Mouret, G.; Bocquet, R.; Cuisset, A.: Full Conformational Landscape of 3-Methoxyphenol Revealed by Room Temperature mm-wave Rotational Spectroscopy Supported by Quantum Chemical Calculations. CHEMPHYSCHEM; 19, 1 - 8, 2018.

Wagner, R.; Bunz, H.; Linke, C.; Möhler, O.; Naumann, K-H; Saathoff, H.. Schnaiter, M.; Schurath, U. Chamber Simulations 585 of Cloud Chemistry: The AIDA Chamber, Proceedings of the NATO Advanced Research Workshop No. 980164 "Environmental Simulation Chambers: Application to Atmospheric Chemical Processes", Barnes, I. and Rudzinski, K. (Eds.), Springer (2006).

Wang, J., Doussin, J. F., Perrier, S., Perraudin E.,Katrib Y., Pangui E., Picquet-Varrault, B.: Design of a new multi-phase 590 experimental simulation chamber for atmospheric photosmog, aerosol and cloud chemistry research. Atmos. Meas. Tech., 4 , 2465-2494, doi:10.5194/amt-4-2465-2011, 2011.

Wang, W.; Wang, Z.; Duan, Y. Performance evaluation of THz Atmospheric Limb Sounder (TALIS) of China. Atmos. Meas. Tech., 13, 13-38, 2020.

595 